\title{
Vulnerability and Intervention Opportunities: Research Findings on Youth and HIV/AIDS in South Africa
}

The N elson M andela Children's Fund (N M CF) seeks comprehensive local solutions to address the negative effects of H IV/ AIDS on children, adolescents, households, and communities. To this end, N M CF initiated the Goelama Project, ${ }^{1}$ which uses a community mobilization strategy to catalyze action by local organizations and government bodies to prevent H IV infection and mitigate the socioeconomic impacts of the disease, particularly as they affect orphans and vulnerable children (OVC).

N M CF recognizes that in order to develop indigenous responses to the epidemic, it is important to conduct research to delineate the problem, identify opportunities for intervention, and measure the effectiveness of interventions prior to replication or scaleup. This summary highlights key findings from an assessment of reproductive and sexual health knowledge and behaviors among nearly 5,000 youth from eight districts in three provinces in South Africa where the Goelama Project is active: M pumalanga, Limpopo, and KwaZulu $\mathrm{N}$ atal.

This research is part of a larger study of 29,338 members of nearly 5,000 households which seeks to identify ways that government and communities can strengthen the socioeconomic capacity of households to care and support OVC. The research was commissioned by N M CF and conducted by D evelopment Research Africa (DRA), with technical assistance from the $\mathrm{H}$ orizons and FRONTIERS programs. The youth component focuses on the sexual and reproductive behaviors of young people in the Goelama intervention areas and factors that may influence these behaviors, such as schooling, orphanhood, knowledge, and involvement in community activities.

\section{Data Collection and Survey Sample}

Between December 2001 and M arch 2002, researchers used a cluster random sample research design to conduct a household survey of youth 12 to 22 years old. Respondents were living in eight districts, each of which is a local government unit under the jurisdiction of the D istrict Council. The study sites and corresponding districts were Ehlanzeni in M pumalanga Province; M opani, Vhembe, and Capricorn in Limpopo Province; and U mkhanyakude, M pukonyoni, and U thungulu, as well as U M lalazi, $\mathrm{M}$ thonjaneni, and $\mathrm{N}$ kandla municipalities in $\mathrm{K}$ waZulu $\mathrm{N}$ atal.

In each household one youth was selected to be interviewed. In cases where there was more than one eligible youth, quotas established for age and sex guided the selection of the respondent. The final survey sample (2,451 males and 2,539 females) was representative of the larger population by sex, but was overrepresented by age for the age groups 16 to 18 and 19 to 22, and underrepresented for the age group 12 to 15. Almost all respondents were unmarried ( 98 percent). 0 ver a third of youth 12 to 18 years old (38 percent) were orphans, meaning that they had lost one or both parents to death. ${ }^{2} \mathrm{~A}$ higher proportion of these youth had lost their fathers ( 24 percent) than mothers ( 5 percent). $\mathrm{N}$ ine percent of youth reported that both parents were deceased.
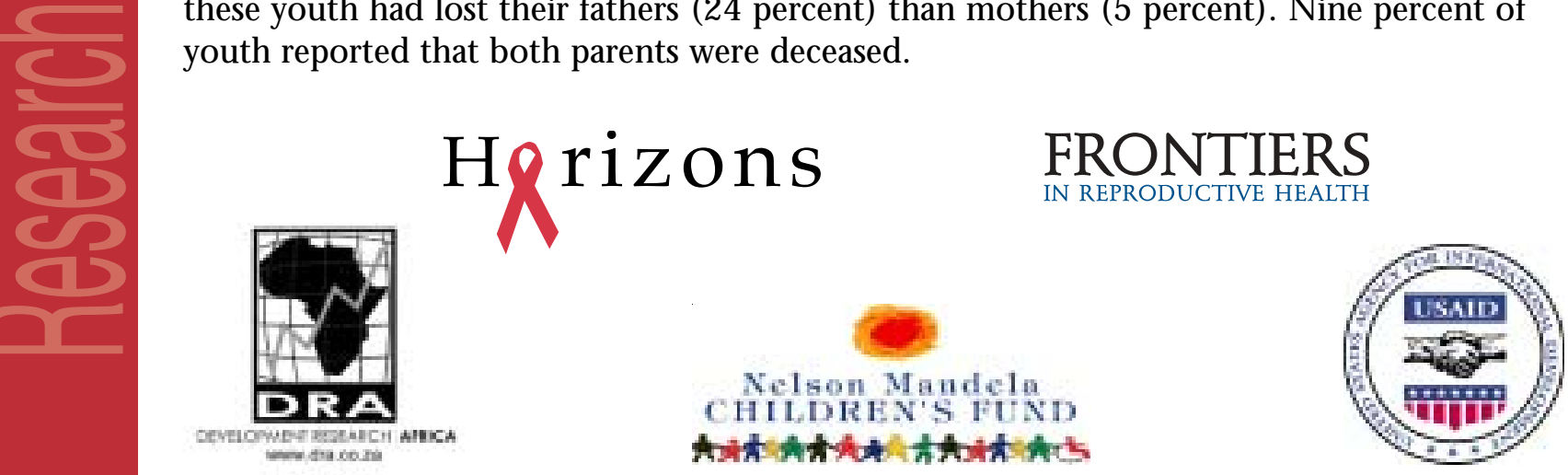
Females and orphans are significantly more likely to be out of school compared to their

counterparts. The study found that 8 percent of youth 12 to 18 years old were no longer attending school. Significant gender differentials were observed in school retention. Females were significantly more likely to be out of school than males ( 10 vs. 5 percent, $p<.001$ ). The reasons mentioned by all youth for dropping out of school were financial constraints (34 percent), pregnancy (23 percent), completion of high school education (18 percent), illness ( 5 percent), and poor school performance ( 4 percent). While males aged 12 to 18 years who were not in school were more likely to mention financial constraints ( 43 percent) compared to similarly-aged females ( 30 percent) as a reason for leaving school, females were more likely to leave school because of pregnancy ( 35 percent) compared to males ( 3 percent). All youth of school age (12 to 18 years old) who were no longer enrolled in school indicated that they were unemployed. In interpreting the results, it is important to note that the ado-lescents 12 to 14 years old were younger than the country's legal minimum age of employment (15 years) at the time of the survey. Also, the survey did not ask if the employable youth were involved in the informal sector or seeking employment or other means of generating income.

O rphans aged 12 to 18 years were significantly more likely to be out of school than non-orphans of the same age group (10 vs. 6 percent, $p<.001$ ). O rphans were also more likely to cite financial constraints (42 percent) and sickness ( 8 percent) as reasons for dropping out of school, compared to non-orphans ( 27 percent and 3 percent, respectively).

Fathers play a limited role as guardians of orphans and non-orphans. The mother was the most frequently mentioned guardian by the youth surveyed (35 percent). Although most youth (62 percent) said that both parents were alive, only a third ( 35 percent) of these youth reported that both parents were guardians. In addition to the mother, other key guardians for orphans were a grandparent or other relative. Figures 1 and 2 illustrate the guardianship for both orphans and non-orphans.

Figures 1 \& 2 Guardianship of orphaned and non-orphaned youth 12 to 18 years old $(n=3,314)$
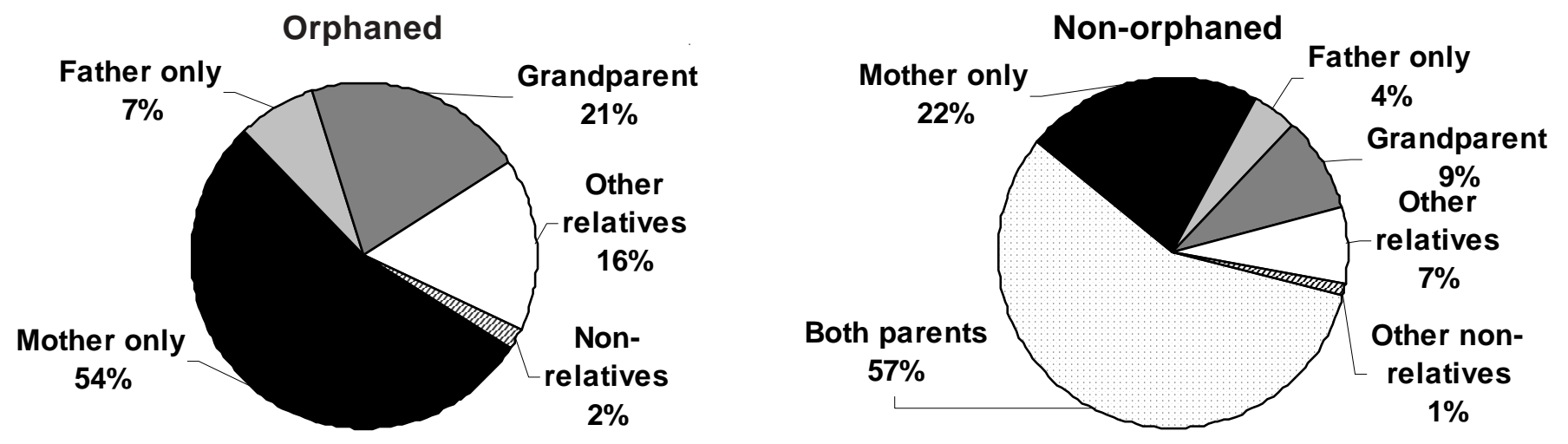

M ost youth do not report having stigmatizing attitudes toward people living with HIV and AIDS, but some feel that orphans are treated badly in the community. The vast majority of youth felt comfortable traveling in the same vehicle with people living with HIV and AIDS (85 percent) and disagreed with the statement that HIV-infected people should be isolated ( 85 percent). A smaller proportion, yet still a majority (54 percent), disagreed with the statement that H IV-infected people should not sell food.

When asked about the stigmatization of orphans, a quarter of youth in the sample felt that orphans are treated differently from non-orphans. O nly 2 percent thought that orphans are treated in a better way, while the vast majority felt that orphans are treated worse, citing the following examples: not being fed or looked after (48 percent), used as servants or laborers (40 percent), physically abused (30 percent), verbally abused (26 percent), teased in school (12 percent), rejected (11 percent), and sexually abused (10 percent). Because opinions may be based on hearsay rather than experience and observation, researchers also asked orphans this 
question. A similar proportion of orphans (25 percent) said that they were treated differently, and in most cases worse, than non-orphans. O n several measures, a slightly greater proportion of orphan respondents compared to non-orphan respondents reported that orphans are teased at school (16 vs. 10 percent), isolated ( 23 vs. 20 percent), and experience rejection (13 vs. 10 percent). But orphan respondents were less likely to state that they are used as servants ( 33 vs. 45 percent) and not fed or looked after ( 45 vs. 50 percent), compared to non-orphan respondents. While both perspectives support the existence of negative treatment of orphans by the community, further investigation is required to gain insight into the community dynamics underlying differential treatment of orphans.

Reproductive and HIV/ STI-related knowledge and awareness are uneven among youth. Although not sufficient alone, knowledge is an important factor in changing risk-taking behavior. The study found that awareness of HIV/ AIDS was high (97 percent), although knowledge of ways to prevent HIV infection was skewed toward consistent condom use. Eighty-nine percent mentioned this H IV prevention method, but abstaining from sex and staying faithful to one partner were mentioned by much smaller proportions of youth (32 percent and 23 percent, respectively). O ther ways to prevent H IV that were mentioned included using gloves (22 percent), avoiding blood contact ( 22 percent) and not sharing razors and/ or needles (11 percent). Less than 5 percent of youth said they didn't know how to prevent H IV or mentioned an incorrect method. Eighty-five percent were aware that a pregnant woman could transmit $\mathrm{HIV}$ to her baby before and during childbirth, while and two-thirds (67 percent) knew about the potential for transmission during breastfeeding. J ust above half of youth ( 57 percent) knew that something could be done to prevent an HIV-positive mother from transmitting HIV to her unborn child.

There were significant gender differences in youth awareness of mother-to-child transmission of H IV and its prevention. Females were more aware than males that a pregnant woman can transmit HIV to her baby before and during childbirth ( 87 vs. 84 percent; $p<.01$ ), that H IV can be transmitted during breastfeeding (72 vs. 61 percent; $p<.001$ ), and that something can be done to prevent an H IV-positive mother from transmitting HIV to her unborn child (64 vs. 51 percent; $p<.001$ ). Knowledge of the existence of an H IV test ( 79 percent) and dual protection methods ( 86 percent) was also high and showed significant gender differences $(p<0.001)$. Females were more likely to report being aware of the existence of an H IV test (82 percent) and dual protection methods ( 87 percent) than were males ( 76 percent and 85 percent, respectively). O verall, females were more aware of how to become infected with HIV (mean knowledge score $=1.95$ ) or how to avoid H IV infection (mean knowledge score $=1.87$ ), compared to males (mean knowledge scores $=1.77$ and 1.67 , respectively).

Sixty-three percent of youth had heard of sexually transmitted infections (STIS). T wenty-one percent of all youth did not know any STI symptoms in men, and 30 percent did not know any STI symptoms in women. Another 17 and 14 percent of youth mentioned incorrect STI symptoms in men and women, respectively.

Contraceptive awareness among youth was higher for the male condom (94 percent) than for the injection methods ( 74 percent), the pill ( 66 percent), and the female condom ( 58 percent). 0 ther contraceptive methods, such as the intrauterine contraceptive device (IUD), female sterilisation, male sterilisation, diaphragm, foam/ jelly, emergency contraceptives, lactation amenorrhoea, rhythm, and withdrawal were known by less than a quarter of youth each. The menstrual cycle was not well understood by respondents, as indicated by the fact that only 7 percent knew the correct time in the cycle when a woman is most likely to get pregnant. There were significant gender differences in knowledge of most contraceptive methods. For example, females were significantly more aware than males of the pill ( 72 vs. 61 percent; $p<.001$ ); IU D (18 vs. 6 percent; $p<.001$ ); injection ( 79 vs. 68 percent; $p<.001$ ); and female sterilisation ( 27 vs. 14 percent; $p<$ .001 ). M ales were significantly more aware than females of rhythm ( 9 vs. 5 percent; $p<.001$ ) and withdrawal (28 vs. 16 percent; $p<.001$ ).

\footnotetext{
$M$ ales initiate sex at an earlier age than females and are more likely to report more than one partner in the previous year. Forty-five percent of youth respondents 12 to 20 years old reported ever having sex in their lifetime $(n=2,235)$. M ore male respondents had had sex (47 percent) than female respondents ( 42 percent). Three times as many males ( 24 percent) compared to females ( 8 percent) had had
} 
sex before reaching 15 years of age. This gender differential prevailed throughout adolescence: 48 percent of males and 35 percent of females had had sex before reaching 18 years of age. Eight percent of sexually experienced youth had had no sexual partners during the 12-month recall period, and males were significantly more likely than females to report being abstinent during this time (11 vs. 4 percent; $p<.001$ ).

About one third ( 31 percent) of sexually experienced youth had had more than one sexual partner during the 12 months preceding the survey. Females were significantly less likely than males to report having multiple partners in the previous year (13 vs. 49 percent; $p<.001$ ), and were significantly more likely than males to report having had only one partner in the past year (83 vs. 40 percent; $p<.001$ ). Sexually experienced youth who belonged to a religious group were significantly less likely to have had multiple sexual partners during the past year than were youth who did not belong to a religious group (28 vs. 41 percent; $p<.001$ ).

Current contraceptive use is high among sexually experienced youth. Youth were asked if they or their partner had ever used and were currently using various contraceptive methods (see Table 1). T wo-thirds of sexually experienced youth reported that they were currently using a contraceptive method. The male condom was the most popular method reported for current and ever use by both male and female youth. $\mathrm{N}$ ot surprisingly, a significantly higher proportion of females than males reported the use of injectables, while a higher proportion of males compared to females reported the use of condoms.

Table 1 Ever and current contraceptive use among sexually experienced youth (\%)

\begin{tabular}{lcccc}
\hline $\begin{array}{l}\text { Contraceptive } \\
\text { method }\end{array}$ & \multicolumn{2}{c}{ Ever use } & \multicolumn{2}{c}{ Current use } \\
& $\begin{array}{l}\text { Males } \\
(\mathbf{n = 1 , 1 6 1 )}\end{array}$ & $\begin{array}{c}\text { Females } \\
(\mathbf{n}=\mathbf{1 , 0 7 4})\end{array}$ & $\begin{array}{c}\text { Males } \\
(\mathbf{n = 1 , 1 6 1 )}\end{array}$ & $\begin{array}{c}\text { Females } \\
(\mathbf{n}=\mathbf{1 , 0 7 4})\end{array}$ \\
\hline Male condom & $69^{*}$ & 54 & $59^{*}$ & 43 \\
Injectables & $23^{*}$ & 46 & $19^{*}$ & 36 \\
Pill & 9 & 13 & 7 & 6 \\
Withdrawal & 12 & 10 & 6 & 5 \\
Any method & 78 & 78 & 69 & 67
\end{tabular}

${ }^{*}$ Any statistically significant differences between males and females $(p<.001)$

Females lag behind males on several measures of condom use, despite risks. Among sexually experienced youth, the proportion using a condom at first sexual intercourse was low (37 percent) (Figure 3). Although females were significantly more likely to have used condoms than males at first sex, this pattern is reversed at last sex.

Figure 3 Condom use at first and last sex among males and females (\%)

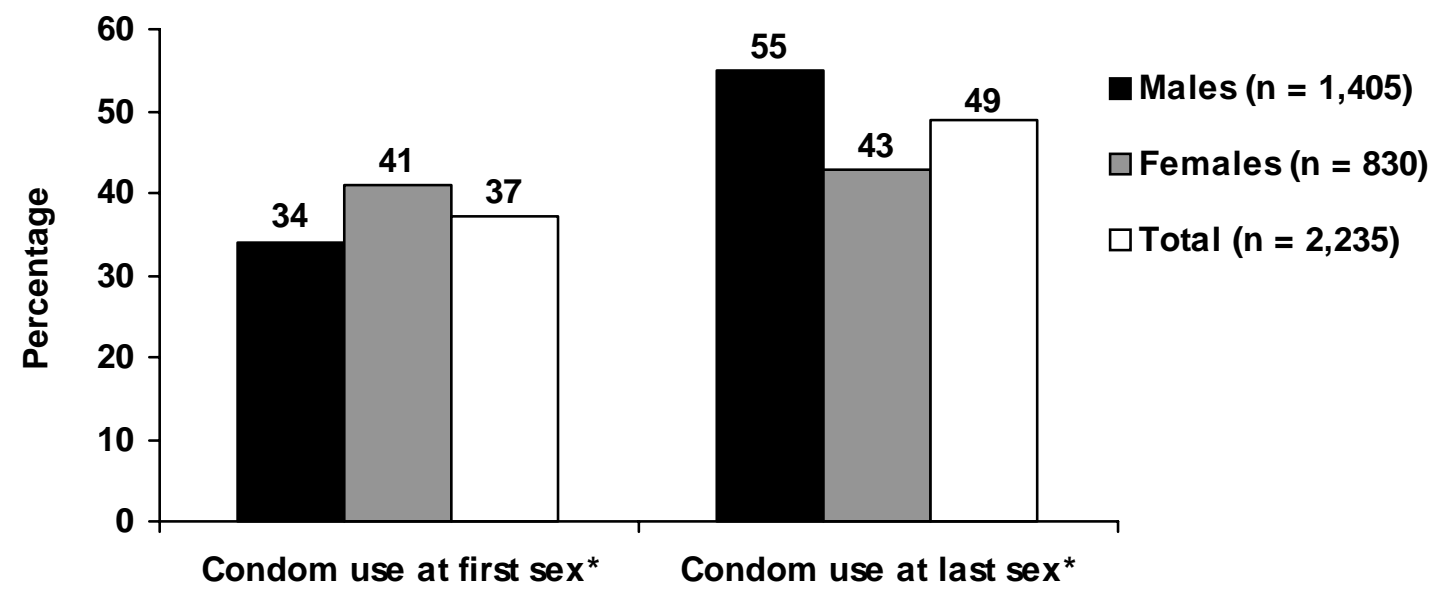

* Statistically significant differences between males and females $(p<.001)$ 
Consistent condom use during every act of intercourse among sexually experienced youth was relatively low (23 percent). Table 2 indicates that youth who reported having one partner in the past year were significantly more likely to have never used a condom and less likely to use a condom consistently compared to youth who reported more than one sexual partnership in the preceding year. Females reported lower consistent use of condoms regardless of the number of partners reported in the past year.

Table 2 Condom use with partner(s) according to the number of partners in the preceding year and gender (\%)

\begin{tabular}{lcccc}
\hline & \multicolumn{2}{c}{ One partner } & \multicolumn{2}{c}{ Multiple partners } \\
& $\begin{array}{cccc}\text { Males } \\
(\mathbf{n}=\mathbf{4 6 2})\end{array}$ & $\begin{array}{c}\text { Females } \\
(\mathbf{n}=\mathbf{8 8 5})\end{array}$ & $\begin{array}{c}\text { Males } \\
(\mathbf{n}=\mathbf{5 5 9})\end{array}$ & $\begin{array}{c}\text { Females } \\
(\mathbf{n}=\mathbf{1 4 7})\end{array}$ \\
\hline Never $^{*}$ & 31 & 44 & 23 & 37 \\
Consistent $^{*}$ & 28 & 20 & 26 & 14
\end{tabular}

* Statistically significant differences between males and females $(p<.001)$

Females were more likely to report they had ever been pregnant (47 percent) than males were likely to report they had made a girl pregnant (10 percent). Of all reported pregnancies, 93 percent were unplanned. In addition, a significantly greater proportion of females reported experiencing STI symptoms in the past three months than males ( 14 vs.10 percent; $p<.05$ ). M ore than half ( 58 percent) of the youth who reported experiencing an STI symptom in the past three months sought treatment from a clinic, doctor, or hospital. There was no significant difference by sex in health seeking behaviour. O nly half (51 percent) of those with an STI symptom notified their partner, and 32 percent were aware that their partner sought treatment. A significantly greater proportion of females than males reported that the partner sought treatment ( 36 vs. 28 percent; $p<.05)$.

Both females and males report pressuring a partner to have sex, but females are twice as likely to have been physically forced to have sex. The study used a range of questions to explore motivations and pressure for having sex. As shown in Table 3, 25 percent and 18 percent of sexually experienced males and females, respectively, reported that they have used verbal persuasion to convince a reluctant partner to have sex. M uch lower figures were reported for engaging in sex for material gain or because of physical force, although twice as many females reported being the victims of forced sex than males.

Table 3 Sexual coercion among sexually experienced males and females (\%)

\begin{tabular}{lcccc}
\hline & $\begin{array}{c}\text { Ever been } \\
\text { physically forced } \\
\text { to have sex }\end{array}$ & $\begin{array}{c}\text { Ever been given } \\
\text { money or gift to } \\
\text { have sex* }\end{array}$ & $\begin{array}{c}\text { Ever convinced } \\
\text { reluctant partner } \\
\text { to have sex }\end{array}$ & $\begin{array}{c}\text { Ever given money } \\
\text { or }\end{array}$ \\
\hline Males $(n=1,156)$ & 3 & 3 & 25 & 3 \\
Females $(n=1,071)$ & 6 & 5 & 18 & 2 \\
Total $(n=2,228)$ & 4 & 4 & 21 & 3
\end{tabular}

* Statistically significant difference between males and females $(p<.05)$

** Statistically significant difference between males and females $(p<.001)$

$M$ any youth are involved in religious and sports activities, but participation in other community groups is minimal. Community groups provide opportunities for young people to learn about reproductive health and sexually transmitted infections, including H IV , and to participate in prevention and care activities. The researchers asked youth about their involvement in different kinds of groups to gauge the potential for integrating HIV/ AIDS activities into ongoing, organized groups. 
As Figure 4 indicates, apart from religious and sports groups, youth participation in music and dance, and in youth community groups, ${ }^{3}$ was low. The figure also highlights significant differences by sex in youth participation by type of group. Less than 1 percent of all youth reported that they were members of other community groups such as stockvels, ${ }^{4}$ burial societies, community gardening groups, sewing groups, development committees, community health organizations, and parent-teacher associations, or school governing body groups.

Youth who were current group members were asked how many times a month they participate in meetings and other activities. On average, youth members of sports groups participated most often (13 times per month), followed by members of music and dance groups ( 9 times per month). The figures for youth community groups and religious groups were six times per month and four times per month, respectively.

Sports and religious community groups have different strengths as entry points for H IV/ AIDS and reproductive health interventions. For example, religious groups have relatively more members than other groups and sports groups have half the membership of religious groups but tend to have more regular meetings per month. Other groups, such as music and dance groups, have few members but a high frequency of participation among its members, and other skills development and livelihood groups such as sewing, gardening, and development and community health groups, should be strengthened and promoted to reach more youth.

Figure 4 Current youth group membership (\%)

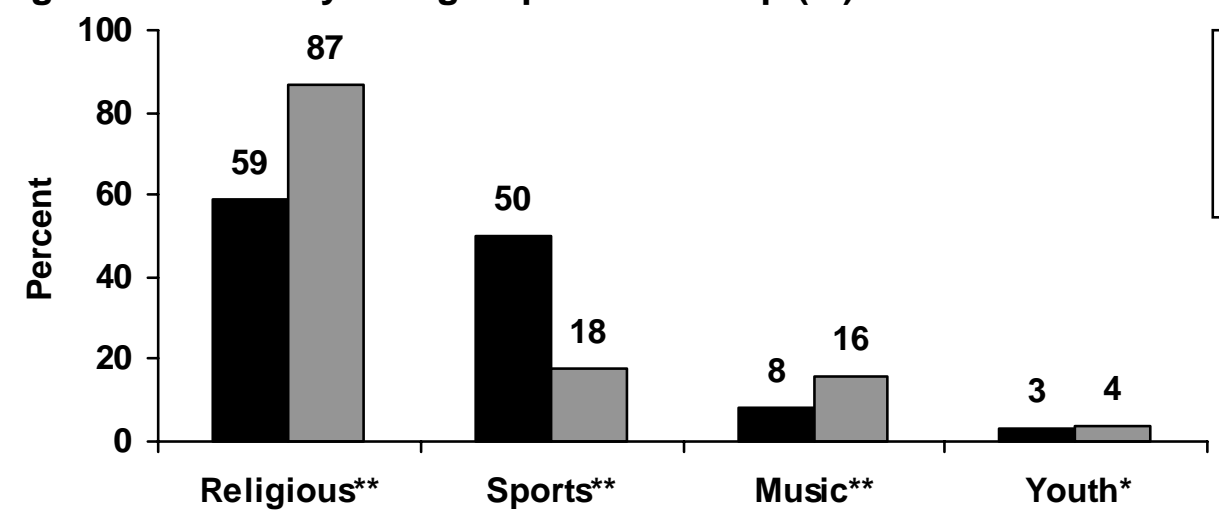

* Statistically significant difference between males and females $(p<.01)$

** Statistically significant differences between males and females $(p<.001)$

Youth report low participation in HIV-related community activities. O nly 3 percent of youth had ever participated in an HIV awareness raising campaign or distributed educational materials. Less than 2 percent of youth had participated in raising awareness of H IV voluntary counseling and testing (VCT) services, or in referring others to VCT or other related health services. In total, 5 percent of youth had ever been involved in any type of H IV-related activity, and there were no significant gender differences in youth participation in such activities. Youth who belonged to a religious group were more likely to have ever participated in any of the activities ( 5 percent) than were those who did not belong to a religious group ( 3 percent).

$M$ any youth help needy community members, although ongoing assistance is less common. To assess youth participation in the provision of assistance to needy members of their community, males and females were asked how often they provide assistance in various activities. As Table 4 indicates, apart from fixing things for neighbors, the majority of both males and females provided some support in caring for children, preparing or giving food, shopping or running errands, and doing household tasks. H owever, a significantly greater proportion of females than males said they provide frequent support for various domestic activities. 
Table 4 Provision of services to neighbors and community members by youth (\%)

\begin{tabular}{|c|c|c|c|}
\hline Activity & $\begin{array}{c}\text { Males } \\
(n=2,450)\end{array}$ & $\begin{array}{c}\text { Females } \\
(n=2,539)\end{array}$ & $\begin{array}{c}\text { All } \\
(n=4,989)\end{array}$ \\
\hline \multicolumn{4}{|c|}{ Care for neighbors' children* } \\
\hline Sometimes & 44 & 43 & 44 \\
\hline Often & 8 & 14 & 11 \\
\hline \multicolumn{4}{|c|}{ Prepare or give food to neighbors* } \\
\hline Sometimes & 49 & 46 & 48 \\
\hline Often & 3 & 13 & 8 \\
\hline \multicolumn{4}{|c|}{ Shopping or run errands } \\
\hline Sometimes & 53 & 51 & 52 \\
\hline Often & 23 & 24 & 24 \\
\hline \multicolumn{4}{|c|}{ Do unpaid housework * } \\
\hline Sometimes & 43 & 47 & 45 \\
\hline Often & 8 & 11 & 10 \\
\hline \multicolumn{4}{|c|}{ Fix things for people* } \\
\hline Sometimes & 38 & 33 & 36 \\
\hline Often & 4 & 5 & 4 \\
\hline
\end{tabular}

\section{Program and Policy Implications}

Education is a valuable means of empowering youth-without proper qualifications, the chances of employment are remote. Schools can be an important setting for reaching youth on HIV and pregnancy prevention. To empower youth in the fight against HIV/ AIDS, the South African government has embarked on a national life skills program that begins in secondary schools and is now expanding to primary schools. Those who drop out of school not only miss out on formal education but also on essential life skills development. Schools also provide supervised time and offer students an alternative to high-risk activities.

L ower rates of school enrollment and retention among females and orphaned youth highlight their potential disadvantage in taking advantage of economic opportunities and in learning essential skills for H IV and pregnancy prevention. Therefore, greater efforts should be made to help these vulnerable groups stay in school and to target programs for school dropouts on income generation, vocational training, and sexual terms negotiation skills to those who have already dropped out.

The results also reveal a need for school and community-based strategies to provide appropriate reproductive health information and services for youth. Of concern is the fact that many youth failed to mention abstaining from sex and being faithful to one partner as ways of preventing H IV infection. Although consistent condom use was well known, it was not well practiced by sexually experienced youth. Therefore, programs should promote primary abstinence for sexually inexperienced youth, and secondary abstinence and consistent condom use among sexually active youth. M essages that promote faithfulness to one partner need to be appropriately crafted and targeted, given the dynamic nature of relationships among youth. Youth should be taught to correctly assess personal risk to HIV/ STI infection.

Youth who experience forced sex are exposed to the immediate risk of infection and unwanted pregnancy. Furthermore, sexual coercion and exchanging sex for material gain may limit youths' ability to negotiate safer sex. A U NFPA study (UNFPA 2000) looked at different forms of sexual motivation and pressure, including verbal persuasion, accepting and offering monetary or material compensation, and use of physical force. Research in 1999 on the economics of sex among adolescents 14 to 22 years old in the Durban metropolitan area found that while youth were reluctant to acknowledge the impact of gifts on their own sexual behaviour and activities, they affirmed that gifts do play a role in negotiating sexual terms and in altering expectations of sexual activity (Kaufman and Stavrou 2002). The researchers found that reported rates of sexual exchange sex were relatively low, although a significant proportion of males and females said they had persuaded a reluctant partner to have sex. The existence of sexual persuasion as well as forced sex, unplanned pregnancy, and unprotected sex among young females and males highlights the need for comprehensive programs for all youth that address peer and partner pressure, sexual rights, and gender-based violence in addition to H IV/ AIDS and STIS. 
Findings from a study on transitions into adulthood in South Africa suggest that connectedness of youth to stable, supportive, and consistent family and community relationships may be a factor in determining the sexual and reproductive health behavior of youth (H orizons 2001). Studies that have included multidimensional community measures often find that structures of opportunities within communities are important to children and adolescents' development. M oreover, the effects of community structures on adolescents are mediated by family processes and by a family's ability to draw on resources within the community (Kaufman et al. 2002).

$\mathrm{H}$ igh levels of youth membership in religious groups and the reported frequent participation in sports groups provide some evidence of community connectedness, and may offer an entry point for community groups focused on HIV/ AIDS or reproductive health to reach more youth with information and services. $M$ oreover, the capacity of sports and religious groups to mobilize youth to play a leading role in H IV-related community interventions, such as promoting VCT, increasing awareness of orphan support programs, and helping to reduce stigma among orphans, should also be explored.

January 2004

1 "G oelama" is a T swana term for nurturing and caring.

${ }^{2}$ Forty-five percent of older youth had also lost one or both parents. For the purpose of this report, unless other wise stated, an orphan refers to a male or female 12 to 18 old who had lost one or both parents.

${ }^{3}$ Youth community groups refer to groups of youth who meet regularly to address challenges facing peers and other community issues.

${ }^{4}$ Refer to indigenous community savings and income-generating schemes that were common during the apartheid era for black economic empowerment.

\section{References}

H orizons Program. 2001. "Are M ore Young People in South Africa U sing Condoms? Study of adolescents' life transitions finds 'connectedness' may be a factor." Horizons Report (Fall). Washington D C : Population Council.

Kaufman C.E and S.E. Stavrou. 2002. “'Bus fare, please' : The economics of sex and gifts among adolescents in urban South Africa," Working Papers 166. N ew York: Population Council.

Kaufman C.E. et al. 2002. "H ow Community Structures of Time and O pportunity Shape Adolescent Sexual Behavior in South Africa," Working Papers 159. N ew York: Population Council.

U NFPA. 2000. Women's Empowerment and Reproductive H ealth-Links throughout the Life Cycle. N ew York: UN FPA.

The study investigators include Kerry Vermaak of D RA Africa, N qobile M avimbela of H orizons/ Frontiers, Jane Chege of Frontiers, and Eka Esu-Williams of Horizons.

\section{(P Population Council}

\section{Hgrizons}

Horizons conducts global operations research to improve HIV/AIDS prevention, care, and support programs. Horizons is implemented by the Population Council in partnership with the International Center for Research on

Women (ICRW), the Program for Appropriate Technology in Health (PATH), the

International HIV/AIDS Alliance, Tulane

University, Family Health International (FHI), and Johns Hopkins University.

\section{FRONTIERS \\ IN REPRODUCTIVE HEALTH}

The Frontiers in Reproductive Health Program (FRONTIERS) applies systematic research techniques to improve delivery of family planning and reproductive health services and influence related policies. FRONTIERS is funded by the U.S. Agency for International Development (USAID) and led by the Population Council in collaboration with Family Health International and Tulane University.

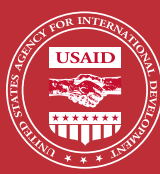

This publication was made possible through support provided by the Office of HIV/AIDS, Bureau for Global Health, U.S. Agency for International Development. The opinions expressed herein are those of the authors and do not necessarily reflect the views of the U.S. Agency for International Development.

For more information, contact:

Population Council/Horizons and Frontiers Communications Units

4301 Connecticut Ave, NW, Suite 280

Washington DC 20008

USA

Tel: $+202-237-9400$

Fax: +202-237-8410

Email: horizons@pcdc.org/frontiers@pcdc.org

http://www.popcouncil.org/horizons

http://www.popcouncil.org/frontiers 